\title{
Comparative anatomical, histological, and histochemical study of liver in human and domestic rabbit
}

\author{
M.Z. Al-Hamdany \\ Department of Anatomy, College of Medicine, University of Mosul, Mosul, Iraq, monahalhamdany @ gmail.com
}

(Received December 21, 2018; Accepted June 16, 2019)

\begin{abstract}
This study was conducted to compare the anatomical histological and histochemical structure of human liver with the liver of domestic rabbits to evaluate the quality of liver of rabbit to be used as a model of mammalian species in the experimental researches. Ten liver biopsies of human (Group I) and same number of liver specimens of domestic rabbit (Group II) were used in this study. The liver specimens were processed and stained with Harris Hematoxylin and Eosin stain and Masson's Trichrome stain and examined under light microscope. For histochemical examination, Periodic Acid Schiff's, Best's carmine and Gomori's Alkaline Phosphatase stains were used. Histomorphometric measurements were done to compare some parameters between the two groups. Transabdominal ultrasound examination was done to compare ultrasonic appearance of the liver in both groups. The work was done from May 2018 to December 2018. The study revealed more lobulated liver of domestic rabbits, hexagonal lobules are mingled with each other in rabbit's liver compared to human, larger hepatocytes, with higher percentage of binucleated hepatocytes and thicker capsule in the human's liver than in the rabbit's liver. Histochemical results revealed less carbohydrates, less glycogen content with less activity of alkaline phosphatase in the cytoplasm of hepatocytes of the human's liver. The ultrasound image revealed denser hyperechoic diaphragm and fibrous capsule, nonhomogenous low echogenicity of parenchyma of the liver of human compared to the rabbit's liver. We conclude that the basic anatomical and histological structure is more or less similar in the human's liver and liver of domestic rabbit but the few differences might be related to the evolutional variations among mammals thus the value of the liver tissue of domestic rabbit to be used in the experimental researches is significant.
\end{abstract}

Keywords: Human liver, Domestic rabbit, hepatocyte, hepatic lobule comparative histological, histochemical Available online at http://www.vetmedmosul.com

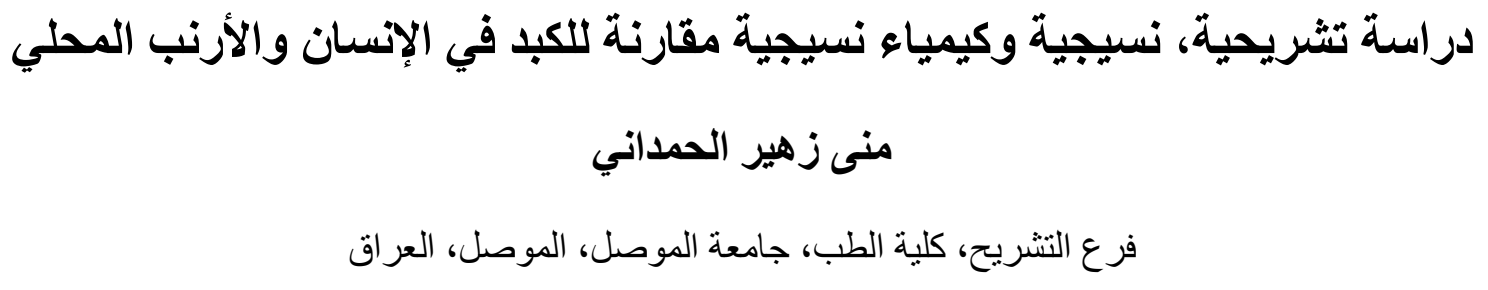

أجريت هذه الدر اسة لغرض مقارنة التركيب التشريحي والنسيجي و الكيمياء نسيجي لكبد الإنسان مع كبد الأرنب المحلي وذللك لمعرفة

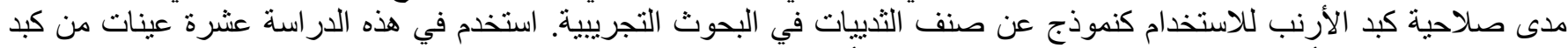

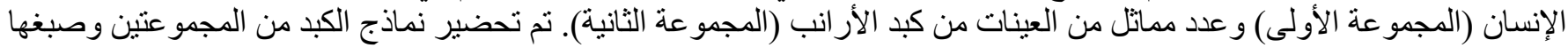

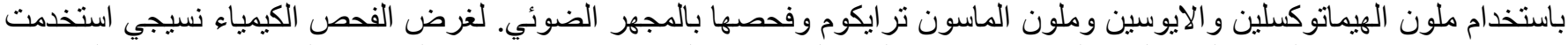

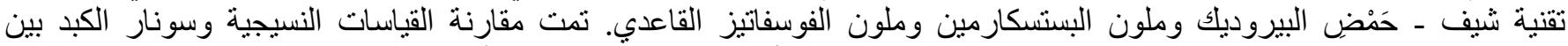

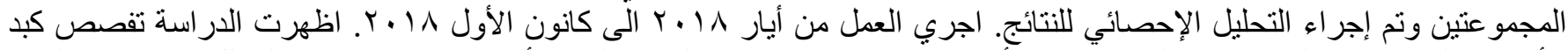

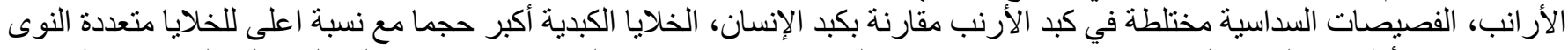
و غلاف انخن. أظهرت النتائج الكيمياء نسيجية انخفاض كمية الكربو هيدر ات بضمنها الكلايكوجين إضافة الى قلة فعالية الفوسفاتيز القاعدي 


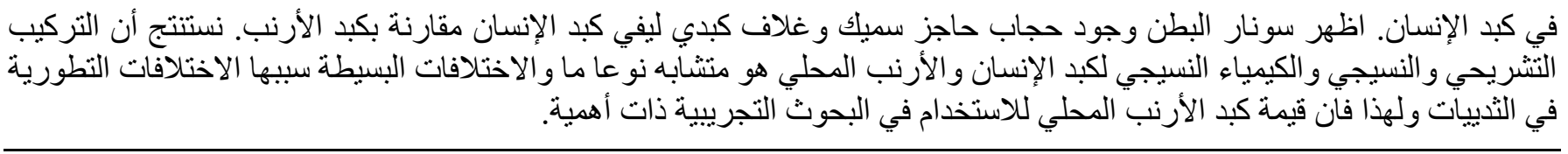

\section{Introduction}

Anatomical and histological structure of the liver varies in different species. The human liver is the largest organ in the body with an average of 1500 gram in weight. It is situated in the right hypochondrium under the right dome of diaphragm (1). Grossly it is divided into right and left lobe in addition to caudate and quadrate lobes in the visceral surface, the gall bladder is situated in the inferior surface of right lobe (2). The portal vein and hepatic artery supply the liver with nutrient-rich and oxygenated blood then the blood drained into the hepatic sinusoids, from which the blood is drained to central veins then to the hepatic veins and inferior vena cava (3). The hepatic lobule is hexagonal consists of plates of hepatocytes separated by sinusoids which drain into the central vein with portal triads at the corners of each lobule with the central vein in the center of each lobule, each portal triad contains a ramification of portal vein, hepatic artery and a bile duct (4). The liver is encapsulated by a connective tissue capsule which is reinforced by the falciform ligament, left and right triangular ligaments and coronary ligament (5). The liver of domestic rabbit is soft lobulated organ lies in the epigastric region below the diaphragm It extends between the costal arches from the $7^{\text {th }}$ right rib to the $9^{\text {th }}$ left rib and touches the left and right abdominal walls (6,7). The liver of domestic rabbit consists of multiple lobules, each composed of irregular plates of hepatocytes with intervening sinusoids which drain into central vein, the cells are polyhedral with acidophilic cytoplasm and prominent nuclei $(8,9)$. Rabbit is a laboratory animal model which has been used in many scientific researches concerned with the assessment of the new pharmaceutical drugs, production of vaccines and for testing the new surgical techniques (10). The ultrasound (US) visualization of the organs correspond to their anatomical and histological interpretation which is apparent in the medical practice as "Golden standard", Previous studies showed that the histological structure is a key factor to obtain objective US results, thus the different echogenicity of the US wave at the same frequency is due to different structure of the liver in different species (11). The lack of studies that compare the anatomical and histological characteristics of human liver and rabbit liver encourage us to do this study aiming to observe, compare and differentiate the anatomy, histology and histochemistry of human liver with that domestic rabbit to assess the quality of liver of domestic rabbit to be used in the experimental studies.

\section{Materials and methods}

In this study, Group I include 10 fresh autopsied normal liver biopsies of human collected from the histopathological laboratory in the Department of Forensic Medicine in Mosul after taking appropriate agreement and ethical approval from Nineveh Health Directorate. Group II includes 10 liver specimens collected from 10 healthy domestic rabbit of both sexes, aged 6-12 months and weighed 1.5-2.5 kg bought from the local market in Mosul. The animals were housed under standard hygienic conditions with free access to food and water. The animals were anaesthetized using intramuscular injection of 50 $\mathrm{mg} / \mathrm{kg}$ Ketamine combined with $5 \mathrm{mg} / \mathrm{kg}$ Xylazine (12). An abdominal incision was done then the peritoneal cavity was opened to see the abdominal viscera clearly. Anatomical topographic localization of liver was done and documented by digital camera (SONY-Cybershot 14.1 Mega Pixels). The liver was extracted from each animal, washed with normal saline solution $(0.9 \%)$ then dried on filter paper, photographed, and fixed in $10 \%$ neutral buffered formalin solution for about 24 hours. The ethical guidelines were approved in the accordance of the international committee of laboratory animal use and care in animal research. The work was done from May 2018 to December 2018.

Specimens of the liver tissue from the two groups were processed into paraffin blocks according to Bancroft et al. (13). then serial sections were obtained from each block using Reichert's Rotatory Microtome and stained with Harris Hematoxylin and Eosin (H\&E) and Masson's Trichrome stains according to Kim et al. (14) then the stained sections were examined using Compound Photo Microscope and some micrographs were taken from some sections using BEl Photonice microscope. For histochemical examination, Periodic Acid Schiff's (PAS) stain was used to detect the carbohydrates, glycogen and mucin, Best's carmine stain to detect glycogen and Gomori's Alkaline Phosphatase-Cobalt method to detect alkaline phosphatase activity in the cytoplasm of the hepatocytes and in the extracellular spaces according to Kumar and Chakrabarti (15). Micromorphometric measurements were done to compare some parameters between Group I and Group II by using the color USB 2.0 digital image camera (Scope Image 9.0- China) which was provided with image processing software. The software of camera was calibrated to all lenses of MicroscopeOlympus-CX31 by aid of $0.01 \mathrm{~mm}$ stage micrometer (ESM11/Japan). Ultrasound study was done to compare ultrasonic appearance of the liver in both groups. The 
transabdominal ultrasound equipment (model Samsung Medison SonoAce R7 Japan) used to examine the liver of Group I and transabdominal ultrasound equipment (model KS-5100Vet Keebomed USA) to examine the liver of Group II. For statistical analysis, computer package (Sigma plot V12.0 / SYSTAT software) was used to conduct the histomorphometrically analysis. Data were presented as Means \pm SE (standard error) and were analyzed using Duncan's test with significant level set as $\mathrm{P}<0.05$ (16).

\section{Results}

The liver of domestic rabbits is dark brown soft lobulated organ composed of five lobes, right lobe, left lobe which is subdivided into lateral and medial lobes, quadrate and caudate lobes. The left medial and lateral lobes are parallel to the right lobe (Figure 1). The diaphragmatic surface (parietal) is convex and lies in close contact with the diaphragm (Figure 2A). The visceral surface is concave and marked by area of porta hepatis and in this surface the left medial lobe appeared to be covered by the left lateral lobe, caudate lobe has a caudate process which is closely related to the right kidney while quadrate lobe is small and covered by fossa for the gall bladder, impressions for the lesser curvature of stomach, first part of duodenum and the portal vein are visible in addition the gall bladder which appeared cylindrical and not reach the anterior border of the liver (Figure 2B).

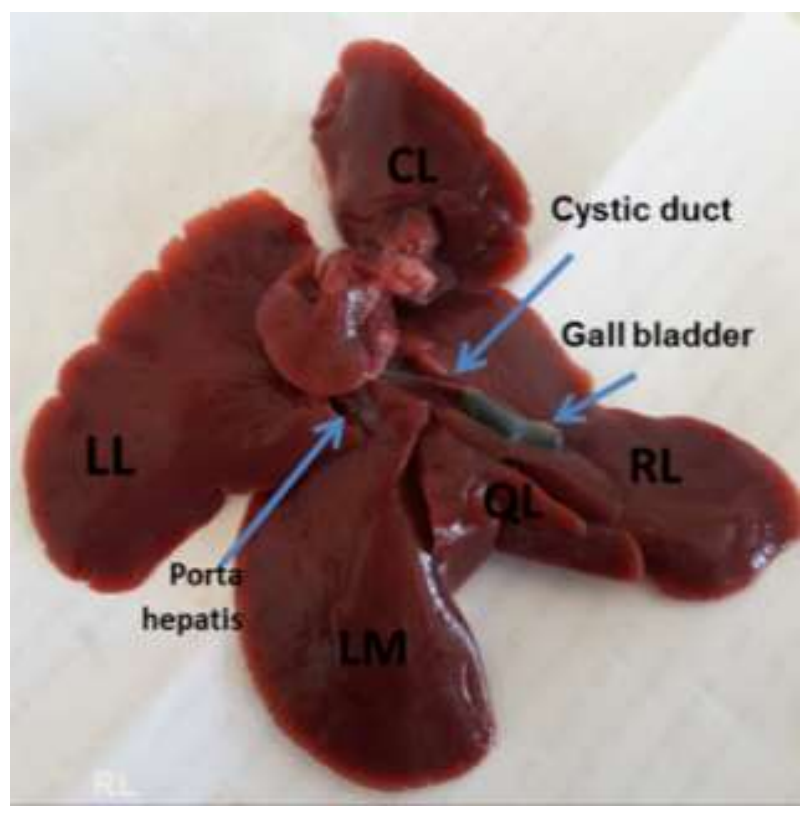

Figure 1: Visceral surface of liver of domestic rabbit showing gall bladder, cystic duct, porta hepatis, right lobe (RL), left lateral (LL) and left medial (LM) lobes, quadrate lobe $(\mathrm{QL})$ and caudate lobe (CL).
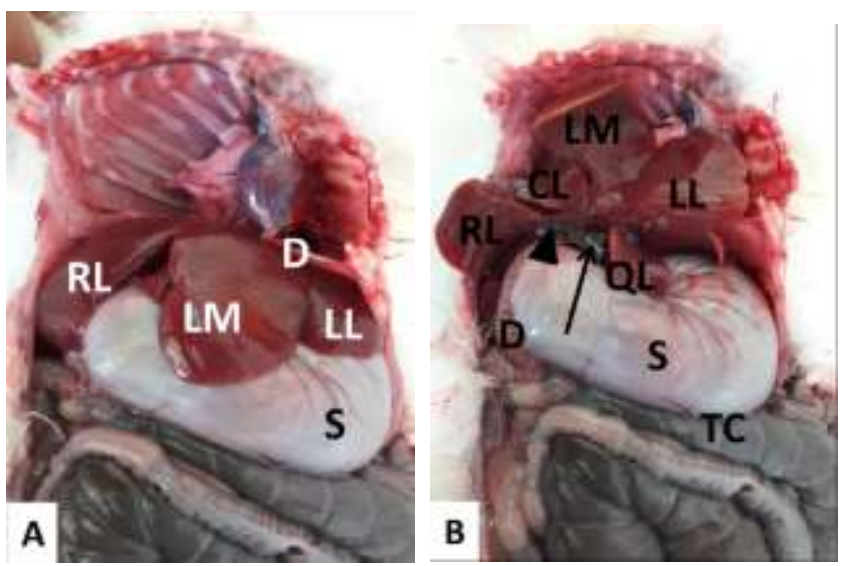

Figure 2A: Anatomical topographic position of liver of domestic rabbit showing the convex diaphragmatic surface (parietal) lies in close contact with the diaphragm (D) and lobes of the liver as in Figure 1. Figure 2B: Anatomical topographic position of liver of domestic rabbit showing the visceral surface in relation with gall bladder (black arrow), stomach (S), first part of duodenum (D), portal vein (arrow head), transverse colon (TC) and lobes of the liver as in Figure 1.

\section{Histological Findings}

The liver of human (Group I) consists of roughly hexagonal lobules separated from each other by connective tissue trabeculae which extend from the capsule, the central vein lies approximately in the center of the hepatic lobule (Figure 3A). While, the liver of domestic rabbit consists of several lobules mingled with each other due to few or absent connective tissue septa between them, random irregular distribution of central veins within the hepatic lobules was observed (Figure 3B). The hepatocyte in the liver of human (Group I) are large hexagonal or polyhedral with central large rounded nuclei and eosinophilic cytoplasm arranged in regular plates separated by sinusoidal capillaries which are lined by flattened endothelial cells and the Kupffer cells which appear spherical in shape with dark cytoplasm (Figure 4A). Whereas, in rabbit's liver (Group II) the hepatocytes are polyhedral with smaller rounded nuclei arranged as irregular plates or cords (Figure 4B). Portal triads in Group I contains branches of hepatic artery, portal vein and bile duct (Figure 5A). In Group II the portal triads lie at the angles of the hepatic lobules with dense connective tissue containing branches of hepatic artery, portal vein and bile duct (Figure 5B). In both groups, the cytoplasm of hepatocytes exhibit obvious vacuolization whereas the hepatocytes adjacent to the bile ducts have a homogenous cytoplasm and their nuclei appear either dark (heterochromatic) or light (euchromatic). Binucleated hepatocytes (diploidy) are present in the liver parenchyma 
of both human and rabbit but its percentage is higher in human $(16 \%)$ than in rabbit $(13 \%)$. On the other hand, the percentage of binucleated hepatocytes is higher near or around the bile ducts and the connective tissue septa in both human and rabbit's liver (Table 1) (Figure 6A and B).

Table 1: Percentage $\%$ of binucleated hepatocytes in liver of human and domestic rabbit

\begin{tabular}{lcc}
\hline Groups & $\begin{array}{c}\text { Human } \\
(\mathrm{N}=10)\end{array}$ & $\begin{array}{c}\text { Rabbit } \\
(\mathrm{N}=10)\end{array}$ \\
\hline Around or near bile ducts & $13 \%$ & $16 \%$ \\
In the parenchyma & $33 \%$ & $42 \%$ \\
\hline
\end{tabular}

\section{Morphometrical findings}

The analysis of all the parameters of micromorphometric measurements revealed a significant difference between the liver of human and domestic rabbit at $\mathrm{P} \leq 0.05$ (Table 2). The micromorphometric examination of liver of Group I and II showed that he capsule in human liver (Group II) is thicker about seven folds more than that of liver of rabbit and is composed of three layers, inner and outer connective tissue layers and a middle layer rich with smooth muscle fibers whereas that of rabbit is composed of one layer consists of connective tissue fibers (Figure 7A and B) (Figure 8A and B) (Table 2). The area of portal triad measured in micometer ${ }^{2}\left(\mu \mathrm{m}^{2}\right)$ in rabbit's liver is more about two folds than in human's liver (Table 2). The diameter of the hepatocyte in human liver is significantly more and the nuclear diameter is significantly larger than that of liver of rabbit (Table 2). The mean diameter of hepatocytes cords or plates is significantly less in human liver consisting of one cell thickness while hepatic cords of rabbit's liver has one or two hepatocyte thickness (Figure 7C and D ) (Table 2). The number of central veins per field appeared more in human liver but the mean diameter of central vein is recorded to be higher in the liver of rabbit (Figure 7E and F) (Table 2). Irregular shaped sinusoids with varied diameter extended among the hepatic plates in both human and rabbit's liver but the mean diameter of hepatic sinusoids is significantly higher in rabbit's liver (Table 2). The diameter of bile ductule is significantly more in rabbit's liver whereas the diameter of hepatic arteriole and portal venule is more in the liver of human (Table 2).

Table 2: Different histomorphometrical parameters $/ \mu \mathrm{m}$ of liver in human and rabbit $(*=\mathrm{P}<0.05)$

\begin{tabular}{lcc}
\hline Groups Parameters & human Means \pm SE & rabbit Means \pm SE \\
\hline Capsule thickness & $69.59 \pm 3.399$ & $9.9 \pm 1.284 *$ \\
Portal area $/ \mu \mathrm{m}^{2}$ & $305504.95 \pm 4315.099 *$ & $774260.2 \pm 1882.242$ \\
Hepatocyte diameter & $16.03 \pm 1.43$ & $12.9 \pm 1.056 *$ \\
Nucleus diameter & $5.09 \pm 0.384$ & $3.79 \pm 0.296 *$ \\
Hepatic cord thickness & $16.24 \pm 0.989$ & $24.05 \pm 1.982 *$ \\
Central vein long diameter & $83.23 \pm 4.253$ & $79.26 \pm 1.439$ \\
Central vein short diameter & $67.87 \pm 10.107$ & $103.63 \pm 5.448 *$ \\
Sinusoids diameter & $7.73 \pm 1.131$ & $9.59 \pm 0.801 *$ \\
Hepatic arteriole diameter & $86.85 \pm 3.69$ & $45.15 \pm 5.851 *$ \\
Bile ductule diameter & $47.66 \pm 7.928$ & $121.11 \pm 2.849 *$ \\
Portal venule long diameter & $496.25 \pm 13.403$ & $303.92 \pm 17.156 *$ \\
Portal venule short diameter & $240.92 \pm 3.952$ & $156 \pm 6.139 *$ \\
\hline
\end{tabular}

Star mean there is a significant difference between human and rabbit

\section{Histochemical findings}

The histochemical examination of the liver of human and domestic rabbit revealed less carbohydrates including glycogen content in the cytoplasm of hepatocytes of the human's liver manifested as weak positive reaction to PAS (Figure 9A) compared to strong positive reaction to PAS in the cytoplasm of hepatocytes of the rabbit' liver (Figure 9 B). Specifically less glycogen content in the cytoplasm of hepatocytes of the human's liver confirmed by weak positive reaction to Best's carmine stains (Figure 9C) compared to strong positive reaction to Best's carmine in the cytoplasm of hepatocytes of the rabbit' liver (Figure 9 D). Marked increase in the activity of alkaline phosphatase manifested as a strong reaction to Gomori's alkaline phosphatase stain in the rabbit' liver as compared to the human liver (Figure $9 \mathrm{E}$ and F).

\section{Ultrasound findings}

The US image of the liver of human revealed dense hyperechoic diaphragm and fibrous capsule (Figure 10A) while the US image of the rabbit's liver revealed the diaphragm and the fibrous capsule as less hyperechoic shadow (Figure 10B). The liver of human showed nonhomogenous low echogenicity of parenchyma observed as dark grey color with finely grainy appearance (Figure 10A) whereas in the rabbit's liver homogenous low echogenicity 
was observed (Figure 10B). The wall of the hepatic duct was hyperechoic compared to the relatively hypoechoic parenchyma in both groups (Figure 10A and B). Portal vein showed increased echogenicity related to the strength of the echo signal reflected by tunica adventitia and lamina propria (Figure 10A and B).

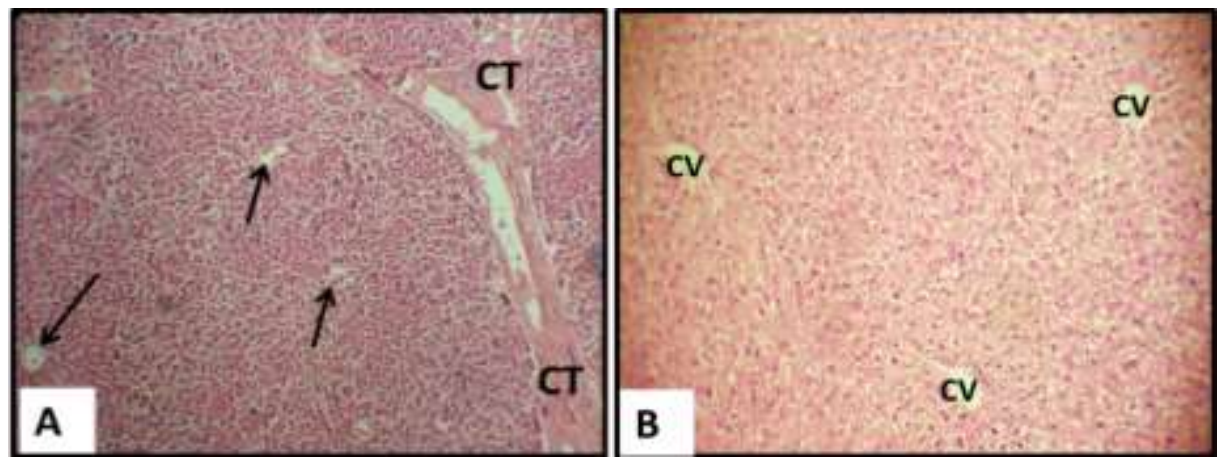

Figure 3A: Photomicrograph from human's liver (Group I) showing the hepatic lobules with central veins (black arrows) separated by thin connective tissue (CT) trabeculae (H\&E X 60). B: Photomicrograph from rabbit's liver (Group II) showing the hepatic lobules mingled with absent connective tissue septa between them, random irregular distribution of central veins (CV) (H\&E X 60).

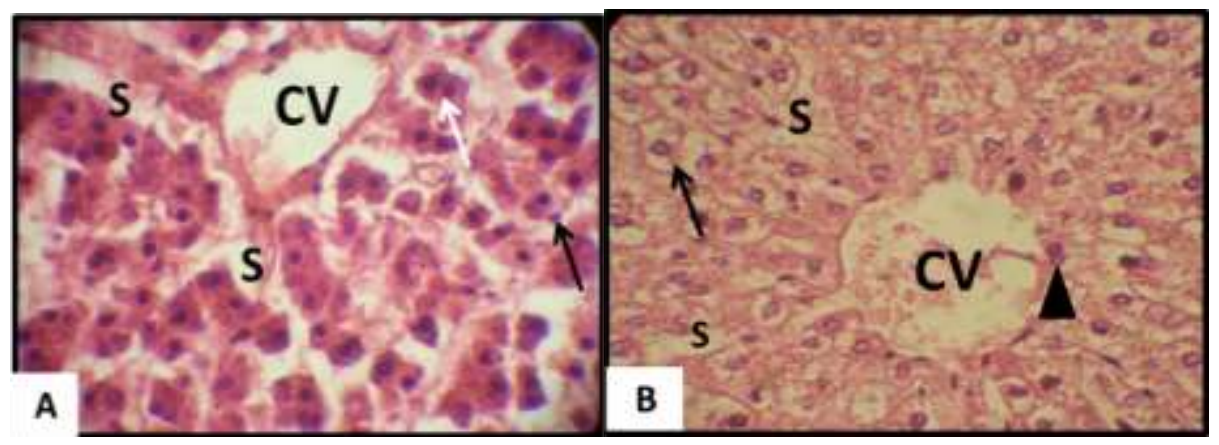

Figure 4A: Photomicrograph from human's liver (Group I) showing the central vein (CV), binucleated hepatocytes (white arrow), sinusoidal capillaries(S), Kupffer cells (black arrow) (H\&EX600). B: Photomicrograph from rabbit liver (Group II) showing the central vein $(\mathrm{CV})$, plates of hepatocytes (black arrow) some are binucleated (arrow head), hepatic sinusoids (S) (H\&E X 600).

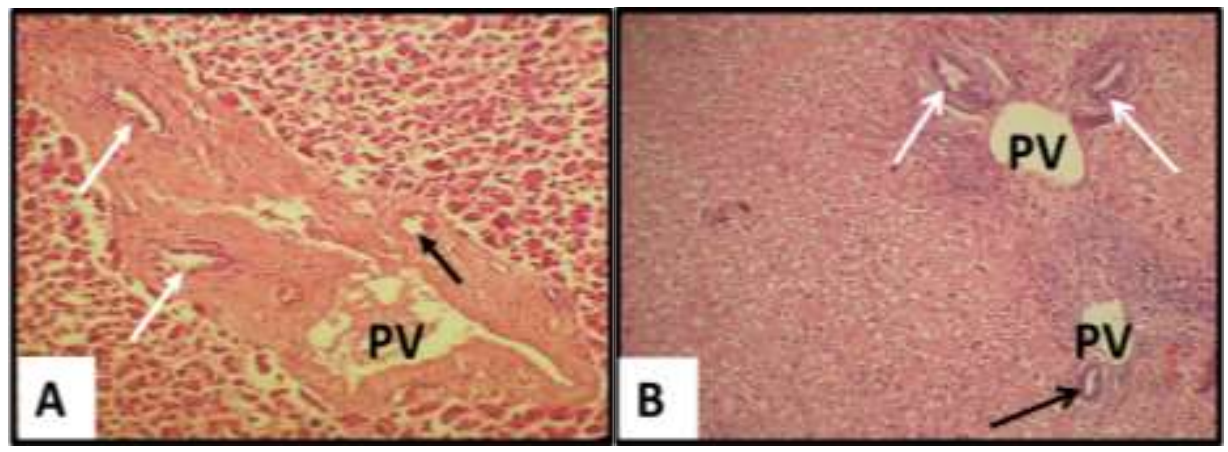

Figure 5A: Photomicrograph from human's liver (Group I) showing portal triads contains connective tissue and branches of hepatic artery (black arrow), portal vein (PV) and bile duct (white arrows) (H\&E X 150). B: Photomicrograph from rabbit's liver (Group II) showing the portal area containing portal vein (PV), hepatic artery (white arrows), and bile duct (black arrow) (H\&E X 150). 


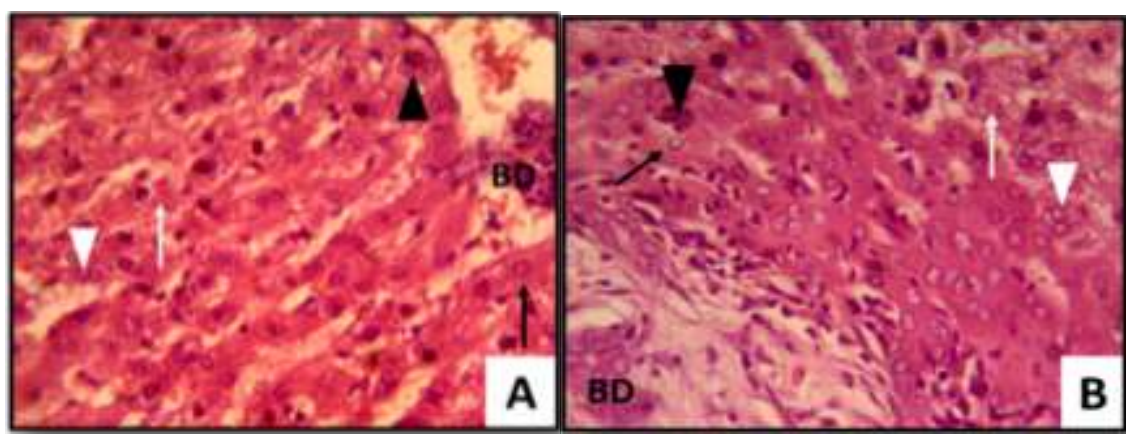

Figure 6 A and B: Photomicrograph from human's liver (A) and Photomicrograph from rabbit's liver (B)showing hepatocytes with vacuolization of cytoplasm (white arrows), homogenous cytoplasm (black arrows), binucleated hepatocytes with dark stained nuclei (black arrow head) and other binucleated hepatocytes with light stained nuclei (white arrow head) (H\&E X 400).

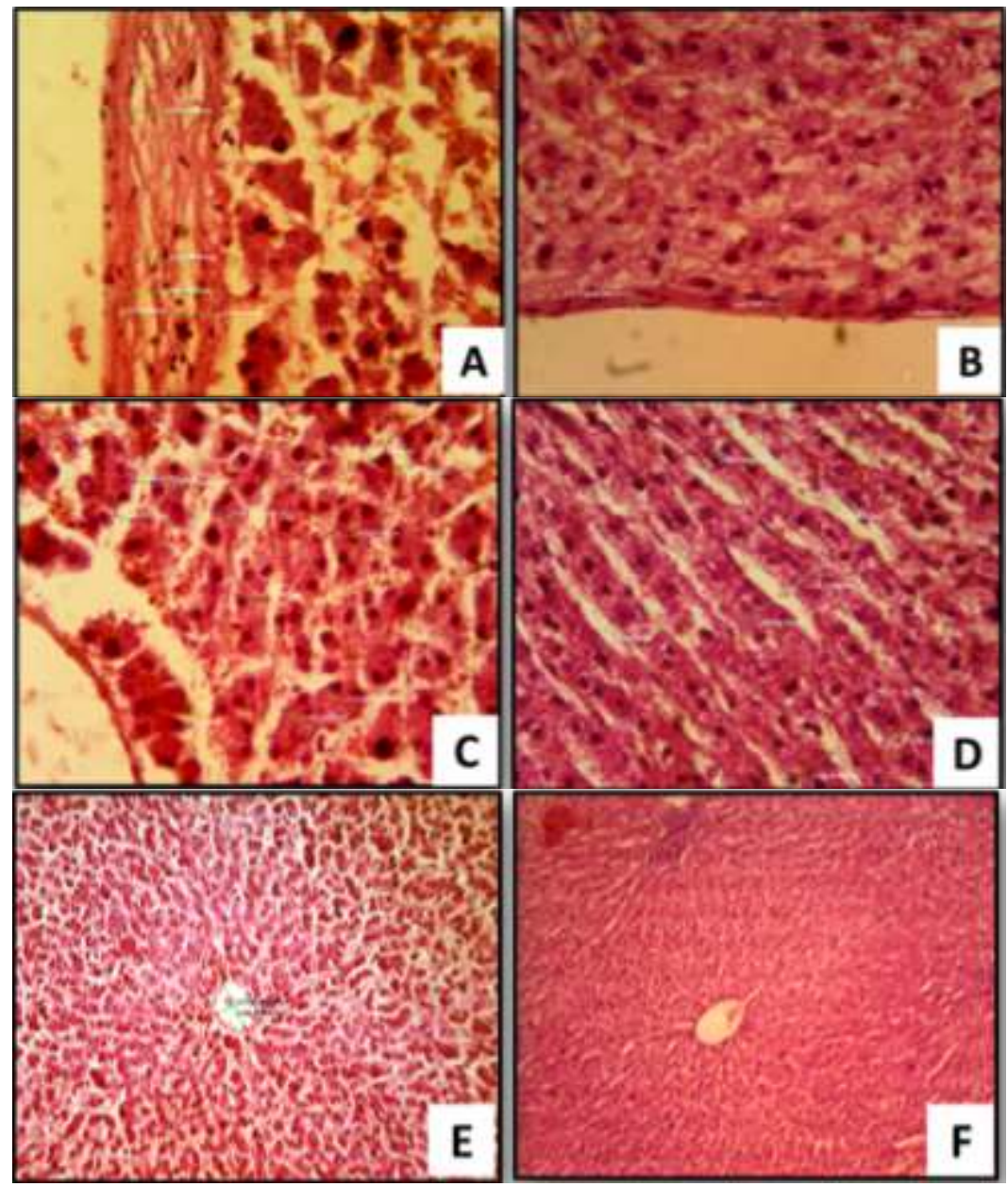

Figure 7: Photomicrograph from human's liver (A) showing thicker capsule than that of liver of rabbit (B)(H\&E X 400). The hepatocytes cords or plates consist of one cell thickness in human liver (C), one or two hepatocyte thickness in rabbit's liver (D) (H\&E X 400). The diameter of central vein is less in human liver (E) than that of liver of rabbit (F) (H\&E X 100). 

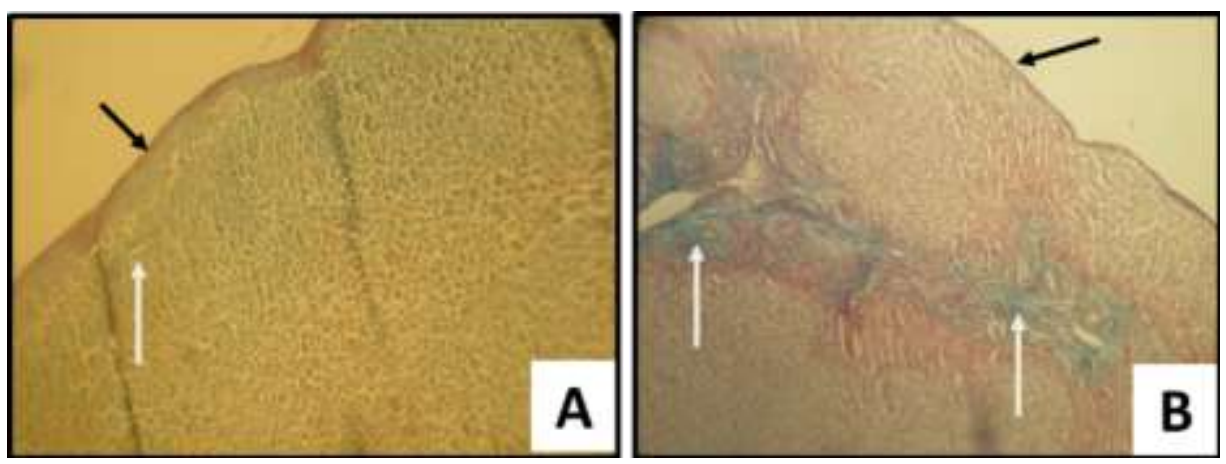

Figure 8: Photomicrograph from human's liver (A) showing thicker capsule (black arrows) more collagen fibers in the portal triad (white arrows) than that of liver of rabbit (B) (Masson's TrichromeX100).
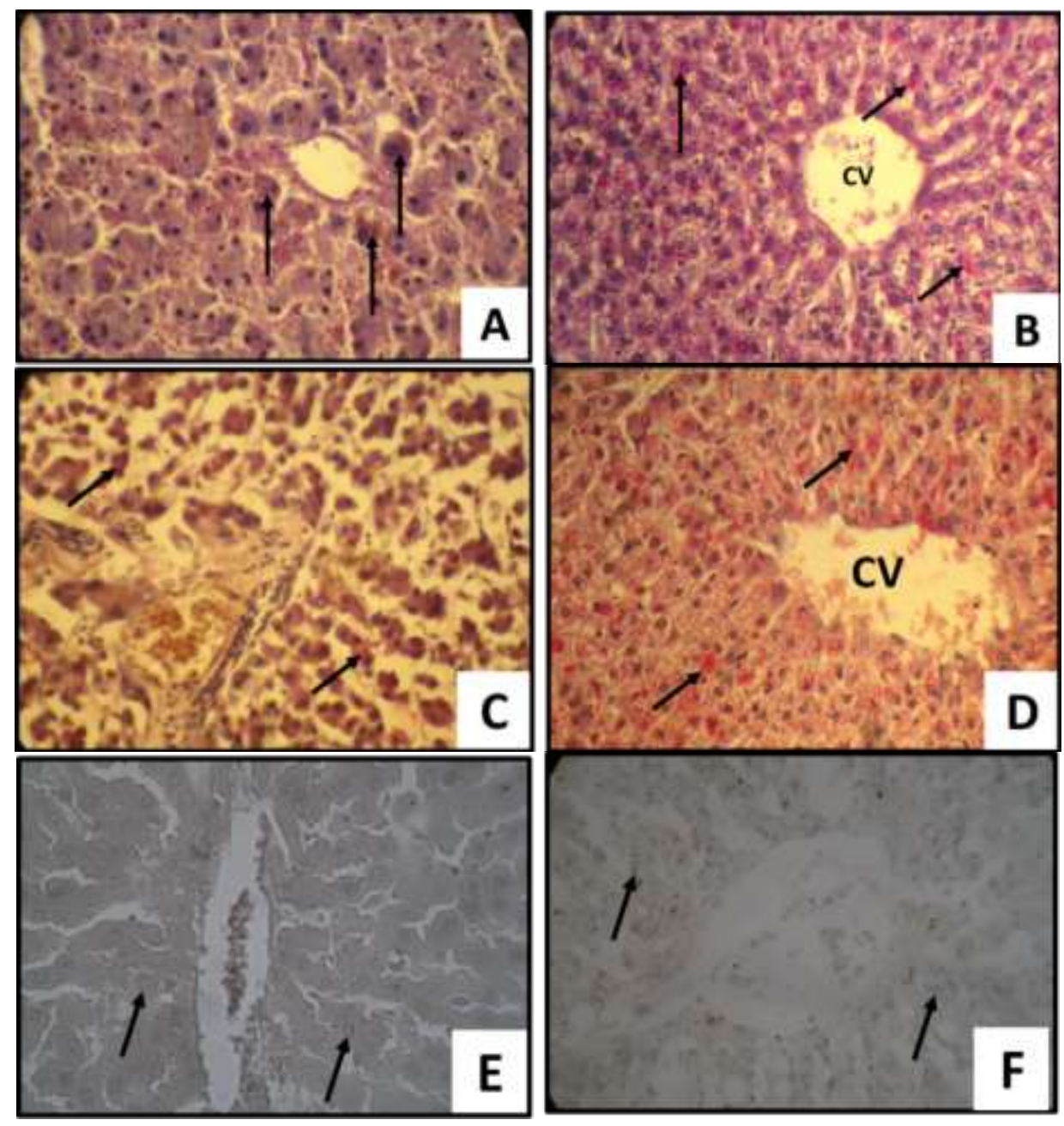

Figure 9: Photomicrograph from human's liver (A) showing weak positive reaction to PAS compared to strong positive reaction in the cytoplasm of hepatocytes of the rabbit' liver(B) (PASX 400). Weak positive reaction to Best's carmine stain in the cytoplasm of hepatocytes of the human's liver (C) compared to strong positive reaction to Best's carmine in the cytoplasm of hepatocytes of the rabbit' liver (D) (Best's carmineX400). Weak reaction to Gomori's alkaline phosphatase stain in the human liver (E) as compared to rabbit' liver as black dots in the cytoplasm (F) (Gomori's alkaline phosphatase stain X400). 


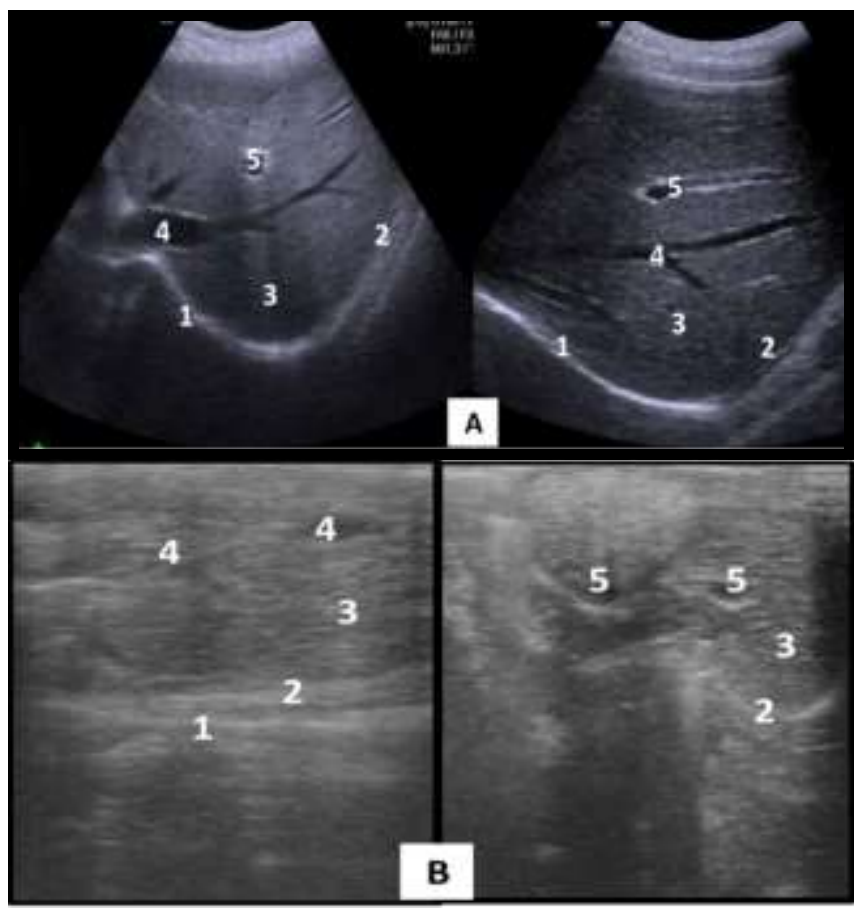

Figure 10: US image of human's liver (A) and US image of rabbit's liver (B) showing (1) diaphragm, (2) capsule (3) liver parenchyma (4) portal vein (5) bile duct.

\section{Discussion}

In the present study, the anatomical close contact of the parietal surface of liver of domestic rabbit with the diaphragm and the relation of the left part of visceral surface with the lesser curvature of the stomach and right part with the cecum are similar to the finding previously reported by Verma et al. (8). The human's liver has four lobes when it is defined by gross anatomical appearance, and eight segments by its internal architecture and knowledge of anatomy is required for good surgical outcome and diagnostic imaging (17). In most mammals, the liver consists of multiple lobes but the arrangement and number of the lobes varies considerably among the domestic animal species like cow, goat and sheep (18). Characteristic lobation of the rabbit's liver into five lobes right, left lateral, left medial, quadrate and caudate lobes which is composed of caudate process and papillary process confirmed the results of Stamatova et al. (19) and Verma et al. (8) who mentioned that the left lateral lobe was slightly larger than the right one and the quadrate lobe is the smallest of all other lobes of rabbit's liver.

In both groups, hepatocytes adjacent to the bile ducts with heterochromatic or euchromatic nuclei could be attributed to the mitotic activity and regenerative characteristic feature of mammalian liver which is capable of recovering after a variety of injuries either via replication of the existing cells or via differentiation from specialized stem cells as mentioned by Stanger in (20) and AlHamdany and Al-Hubaity (21). Higher percentage of binucleated hepatocyte (polyploidization) in the in parenchyma of human's liver 16\% than in rabbit's liver 13\% is explained by more nourishment and extensive blood supply of the peripotal hepatocytes in the region close to the portal triads and in septa separating between the lobules, this findings are in agreement with $40 \%$ percentage of polyploidization in the hepatocytes of human's liver reported by other workers which is considered as an indicator of aging process and could be stimulated by metabolic stress as surgical resection, toxic stimulation, and oxidative damage $(22,23)$. Thick capsule of liver in human as compared with that of liver of rabbit similar to the finding previously reported by Gupta et al. (24) in the liver of neonatal rabbits. Wider area of portal triad in rabbit's liver than in human liver might be due to less diameter of hepatic arteriole and portal venule allowing more area for connective tissue and this agree with the finding of Verma et al. (8). The significant larger diameter of the hepatocyte and their nuclei and subsequently less diameter of hepatocytes cords consisting of one cell thickness in the liver of human might be due to more intense metabolic activity and functions of the hepatocytes in the liver of human corresponding to the different size and surface area between the two species in order to maintain whole body homeostasis similar observations have been noticed by Kietzmann (25).

In the present study, Less carbohydrates and specifically less glycogen content in the cytoplasm of hepatocytes of the human's liver as compared to the rabbit's liver agree with the finding of previous workers who mentioned that greater metabolic activity and larger surface area of the human body lead to rapid depletion of glycogen droplets stored in the cytoplasm of hepatocytes and subsequently weak positive reaction to PAS and Best's carmine stains and this depends also on the nutritional status of the individual (26). Gomori's method was used to determine alkaline phosphatase enzyme activity in the hepatocytes of human and rabbits, the degree of blackness of the cell cytoplasm is attributed to the activity of the enzyme present (27). Strong reaction to Gomori's alkaline phosphatase stain in the rabbit' liver as compared to the human liver is similar finding had been established by Voieta et al. (28).

The characteristic ultrasound image of the liver in both species explain the anatomical position and histological features as the arrangement of hepatocytes, sinusoidal capillaries and fibrous capsule, this is correlated with the application of the imaging techniques for the anatomical study of the organs (29). The histological interpretation of the obtained US visualization of liver is due to the scattering character of the echo-signal, generated by 
perivascular connective tissue, parenchyma, and biliary duct system (30) while in human's liver, micromorphological features of the soft tissue are the "Gold standard" which determine the US anatomical images (31).

The variability in the US image of the liver between human and rabbit is due to variable acoustic impedance of the tissue and not related to the orientation of the transducer to the field of study $(32,11)$. The echogenic shadows of the rabbit's liver reflects the histological features of the liver and biliary ducts with variable US acoustics at the same intensity of the US wave in contrast to the ultrasound image of human's liver in which connective tissue is the only morphologic substrate that decides the acoustic properties of the ultrasound appearance (33). The acoustics image of fibrous capsule and hepatic parenchyma in both human and rabbit is related to some ultrasound indices as brightness and contrast according to the grey-white scale, variety of the grey shadow and the speed of the US wave (34).

In conclusion the basic anatomical and histological structure is more or less similar in the human's liver and liver of domestic rabbit but some differences are observed which might be related to the evolution or development variations among mammals. The value of the liver tissue of domestic rabbit to be used in the experimental researches is clearly significant.

\section{References}

1. Standring S. Gray's Anatomy: Anatomical basis of clinical practice. $40^{\text {th }}$ ed. London: Churchill Livingstone; 2008. 1173-1175.

2. Ibukuro K, Fukuda H, Tobe K, Akita K, Takeguchi T. The vascular anatomy of the ligaments of the liver: gross anatomy, imaging and clinical applications. Br J Radiol. 2016;89(1064):20150925. DOI: 10.1259/bjr.20150925.

3. Hansen JT. Netter's clinical anatomy. $2^{\text {nd }}$ ed. New York: SaundersElsevier; 2012. 147- 148 p.

4. Ross MH, Kaya GI, Pawlion W. Histology; a text and atlas with cell and molecular biology. $4^{\text {th }}$ ed. Philadelphia: Lippincott; 2006. 603-626 p.

5. Eroschenko VP. Difiore's Atlas of histology with functional correlations. $11^{\text {th }}$ ed. Philadelphia: Lippincott Williams \& Wilkins; 2008. 277-281 p.

6. Gupta N, PandeyY, Vaish R, Gupta DK. Gross and histomorphological studies of liver in neonatal rabbit (Oryctolagus cuniculus). J of Anim Res. 2017;7(3):575-579. DOI: 10.5958/2277940X.2017.00086.9

7. Trautmann A, Fiebiger J. Fundamentals of the histology of domestic animals. $1^{\text {st }}$ ed. Lucknow: Greenworld Publishers; 2002. 219-224 p.

8. Verma A, Pathak A, Gupta SK, Farooqui MM, Prakash A. Topographical and morphometrical studies on the liver in rabbit (Oryctolagus cuniculus). Indian J Vet Anat. 2015;27(2):3-5 DOI: 10.5958/2277-940X.2017.00086.9

9. Mittal R, Chowdhary D. A pilot study of the normal measurements of the liver and spleen by ultrasonography in the Rajasthani Population. J Clin Diag Res. 2010;4:2733-2736.DOI:55330

10. Yanni AE. The laboratory rabbit: an animal model of atherosclerosis research. Lab Anim. 2000;38:246-256. DOI: $10.1258 / 002367704323133628$

11. Yovcheva KS, Dimitrov R, Yovchev D. Vladova D, Dilek GO, Mihaylovv R. Histological definition for the gray scale ultrasonography of the rabbit liver. Vet Hekim Der Derg. 2018;89(1):32-41.

12. Faris GA, Abd-Almaseeh ZT, Abass BT. Comparative injectable anesthetic protocols in ducks. Iraqi J Vet Sci. 2007;21(1):105115.DOI:10.33899/ijvs.2007.5621

13. Bancroft JD, Cook HC, Stirling RW. Manual of histological techniques and their diagnostic application. Edinburgh; Churchill Livingstone; 1994. 457-458 p.

14. Kim S, Layton C, Bancroft JD. Bancroft's theory and practice of histological techniques. $7^{\text {th }}$ ed. UK: Churchill Livingstone; 2013. 215 $236 \mathrm{p}$.

15. Kumar G and Chakrabarti P. Histological and Histochemical Analysis of the saccusus vasculosus of butter catfish ompok bimacualtus. J Entomology and Zoology Studies 2013; 1(3):22-28.

16. Harris M, Taylor G. Medical statistics made easy. London: Martin Dunitz Company; 2004. 9,16,24,34 p.

17. Patil S, Sethi M, Smita K. Morphological study of human liver and its surgical importance. Int J Anat Res. 2014; 2(2):310-314

18. Madhan K, Raju S. Comparative histology of human and cow, goat and sheep liver. J Surg Acad. 2014;4(1):10-13.

19. Stamatova K, Dimitrov R, Kostov D, Yovchev D. Anatomical macromorphological features of the liver in domestic rabbit (Oryctolagus Cuniculus). Turkish J Sci. 2012;10(2):85-90.

20. Stanger BZ. Cellular homeostasis and repair in the mammalian liver. Ann Rev Physiol. 2015;77:179-200. DOI: 10.1146/annurev-physiol021113-170255

21. Al-Hamdany MZ, Al-Hubaity AY. The histological and histochemical changes of the rat's liver induced by 5- fluorouracil. Iraqi J Vet Sci. 2014;28(2):95-103

22. Wang M, Chen F, Lau J, Hu Y. Hepatocyte polyploidization and its association with pathophysiological processes. Cell Death Dis. 2017;8(5):e280. DOI: 10.1038/cddis.2017.167.

23. Tahir MT, Hasso RA, AL-Sarraj AA. Morphometrical analysis of liver hepatocyte in rabbits treated with nandrolone decanoate. Med J Basrah Uni. 2009;27(1):23-27.

24. Gupta N, Pandey Y, Vaish R, Gupta DK. Gross and histomorphological studies of liver in neonatal rabbit (Oryctolagus cuniculus). J Anim Res. 2017;7(3):575-579. DOI: 10.5958/2277940X.2017.00086.9

25. Kietzmann T. Metabolc zonation of the liver: The oxygen gradient. Redox Biol. 2017;11:622-630. DOI: 10.1016/j.redox.2017.01.012

26. Hui H, Ma W, Cui J, Gong M, Wang Y, Zhang Y, He T, Bi Y, He Y. Periodic acid-Schiff staining method for function detection of liver cells is affected by $2 \%$ horse serum in induction medium. Mol Med Rep. 2017;16(6):8062-8068. DOI: 10.3892/mmr.2017.7587

27. Njoku VO, Chikezie PC, Kaoje, MA, Monago CC, Uwakwe AA. Kinetic studies of alkaline phosphatase extracted from rabbit (Lepus townsendii) Liver. Asian J of Biochemistry2011; 6: 65-73. DOI: 10.3923/ajb.2011.65.73

28. Voieta I, Queiroz L, Andrade L, Silva L, Fontes V, Barbosa A, Resende V, Petroianu A, Andrade Z, Antunes C, Lambertucci J. Imaging techniques and histology in the evaluation of liver fibrosis in hepatosplenic Schistosomiasis mansoni in Brazil: a comparative study. Mem Inst Oswaldo Cruz. 2015;105:414-421.

29. Langevin H, Rizzo D, Fox J, Badger G, Wu J, Konofagou E, StevensTuttle D, Bouffard N, Krag M. Dynamic morphometric characterization of local connective tissue network structure in humans using ultrasound. BMC Syst Biol. 2007;1:25.

30. Pawlicki A, Dapore A, Sarwate S, Brein W. Three-dimensional map analysis of rabbit liver. J Acoust Soc Amer. 2011;130:334-338. DOI: 10.1186/1752-0509-1-25

31. Langevin H, Rizzo D, Fox J, Badger G, Wu J, Konofagou E, StevensTuttle D, Bouffard N, Krag M. Dynamic morphometric characterization of local connective tissue network structure in humans using ultrasound. BMC Syst Biol. 2007;1:25. DOI: $10.1121 / 1.3646024$ 
32. Stamatova K, Dimitrov R,Dilek OG. Radiographic study of the topography of the hepatic vasculature and bile ducts of the rabbit Bulgarian J of Agricultural Sci.2018;24(3):497-502.

33. Bridal L, Fournier C, Coron A, Leguerney I, Laugier P. Ultrasonic backscatter and attenuation (11-27 MHz) variation with collagen fiber distribution in ex vivo human dermis. Ultrac Imag. 2006;(28):23-40. DOI:org/10.1177/01617346060280010

34. Tsui PH, Zhou Z, Lin Y-H, Hung CM, Chung SJ, Wan YL. Effect of ultrasound frequency on the Nakagami statistics of human liver tissues. PLoS ONE. 2017;12(8):e0181789. DOI: 10.1371/journal.pone.0181789. 